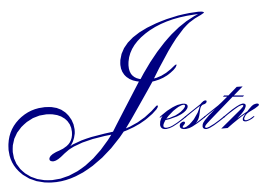

\title{
Modular simulation of a hybrid power system with diesel, photovoltaic inverter and wind turbine generation
}

\author{
Klimis Ch. Karasavvas* \\ Department of Electrical Engineering, Kavala Institute of Technology, St. Lucas 65404 Kavala.
}

Received 5 February 2008; Accepted 5 May 2008

\begin{abstract}
The dynamic behavior and stability of an isolated electric power system, fed by a conventional energy plant and a renewable energy system, is presented in this paper. Matlab/Simulink is the used software for simulating the whole system.
\end{abstract}

Keywords: hybrid power system, simulation model, photovoltaic generator, PWM converter, grid - connected, voltage regulation, reactive power control

\section{Introduction}

Hybrid power systems are designed for the generation and use of electrical power. They are independent of a large, centralized electricity grid and incorporate more than one type of power source. They may range in size from relatively large island grids to individual household power supplies. In general, a hybrid system might contain alternating current (AC) diesel generators, an AC distribution system, a DC distribution system, loads, renewable power sources, energy storage, power converters, rotary converters, coupled diesel system, dump loads, load management options, or a supervisory control system.

\section{AC Diesel Generators}

In a conventional $\mathrm{AC}$ power system, there must always be at least one diesel generator connected to the network. It is required to set the grid frequency and to supply the reactive power.

Conventional generators are normally diesel engines directly coupled to synchronous generators (SG). The frequency of the $\mathrm{AC}$ power is maintained by a governor [1] on one of the engines. The governor functions by adjusting the flow of fuel to keep the engine speed and the generator speed essentially constant. The grid frequency is directly related to the speed of the generator, and is, therefore, maintained at the desired level.

AC networks supply two types of power to their loads: real and reactive. The reactive power in a conventional AC system is supplied by the synchronous generator (as is the real power). This is done in conjunction with the voltage regulator on the generator.

\section{Wind Turbines}

Larger isolated AC electrical systems can use wind turbines

\footnotetext{
*E-mail address: kkaras@teemail.gr
}

ISSN: 1791-2377 (C) 2008 Kavala Institute of Technology. All rights reserved. of the type connected to large central grids. The turbines are typically $10 \mathrm{~kW}$ to $500 \mathrm{~kW}$. Most of the wind turbines (WT) larger than $50 \mathrm{~kW}$ use induction generators. They turn at a nearly fixed speed, based on the frequency of the AC network to which they are connected. They also require an external source to supply their voltage requirements. Thus, in hybrid power systems they operate only when at least one diesel generator is operating.

\section{Photovoltaic Panels - Power Converters}

Sunlight may be used to generate electricity directly via photovoltaic cells. Photovoltaic panels (PV) are inherently a DC power source. As such, they usually operate in conjunction with storage and a separate DC bus. In larger systems, they may be coupled with a dedicated inverter and thus act as de facto AC power source.

For storage or other DC components to be used in conjunction with $\mathrm{AC}$ loads, some type of power conversion capability is required. There are two types of power conversion functions of particular significance for hybrid power systems: rectifying and inverting. Rectifiers convert $\mathrm{AC}$ power to DC. They are commonly used to charge batteries from an $\mathrm{AC}$ source. Inverters convert $\mathrm{DC}$ power to $\mathrm{AC}$ power. They are used to supply individual AC loads from a DC source or battery bank. Inverters are electronic devices. The most modern ones are based on switching power transistors at high frequency. Most inverters are of one of two types: line-commutated of self-commutated. Linecommutated inverters require the presence of an external $\mathrm{AC}$ line. Thus they cannot set the grid frequency if, for example, all of the diesel generators are turned off. Self-commutated inverters control frequency themselves. There are inverters that can operate either independently or in parallel with another generator. These are most versatile, but presently they are also the most expensive.

\section{System Description}

In this paper, the hybrid power system consisting of a diesel generator, a wind turbine, a photovoltaic inverter and a ca- 
pacitor, is considered. In these systems, the voltage and the frequency are controlled by the diesel generator. The wind speed varies with time and so does the village load.

Diesel Generator: $170 \mathrm{kVA}$

Wind Turbine: $50 \mathrm{Hp}$

Photovoltaic Inverter: $30 \mathrm{KW}$

Capacitor: $30 \mathrm{kVAR}$

Load: $90 \mathrm{~kW},-30 \mathrm{kVAR}$

Nominal power: $400 \mathrm{~V}$

Nominal Voltage: $50 \mathrm{~Hz}$

The system block diagram is presented in figure 1 . The diesel generator the wind generator and the photovoltaic inverter are connected in parallel to supply the load.

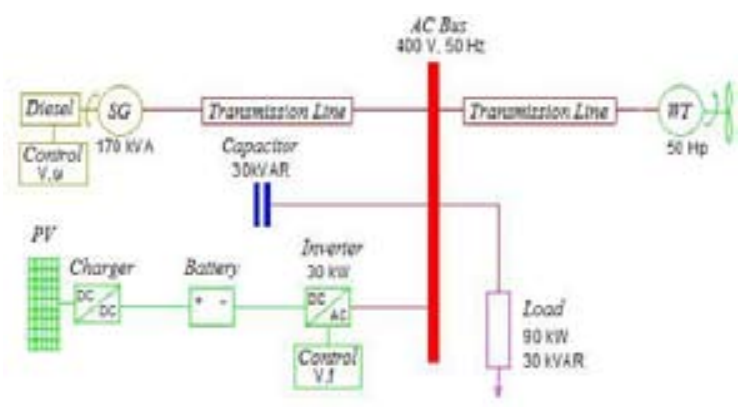

Fig. 1 The system block diagram

The DC to AC inverter is capable of delivering both real and reactive power to the grid. The actual operation of the proposed system is discussed using the simplified equivalent circuit as shown in Fig. 2.

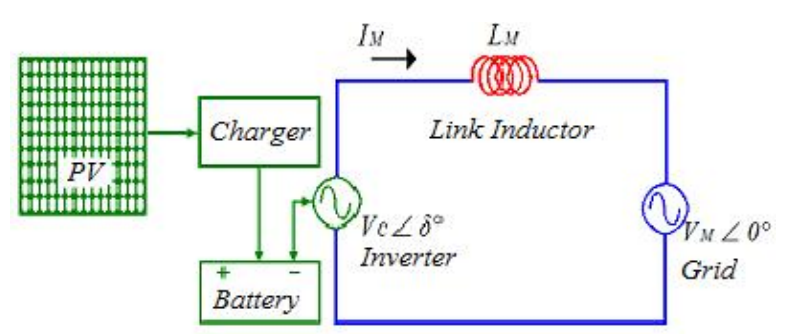

Fig 2 The simplified equivalent circuit

The inverter frequency during this mode is equal to the grid. The grid and the inverter are separated by the link inductor Lm.

Controlling the phase and amplitude of the converter voltage can control the active and reactive power flow from the mains to the load [2]. The function of the inverter as a power flow controller may be simply explained as follows: The inverter is considered to be an AC source connected to the utility grid through an impedance buffer. System frequency variations are continuously monitored at the grid bus and a control signal proportional to the frequency variations is used to vary the phase difference between the inverter and grid buses, thus transferring more or less real power to the utility. Control of the amplitude of the inverter output voltage in relation to the grid bus voltage regulates reactive power flow.

Referring to Fig. 2, the power flow through the link inductor, is as follows [3]:
Real Power: $P_{M}=\frac{V_{M} V_{C}}{\omega L_{M}} \sin (\delta)$

Reactive Power: $Q_{M}=\frac{V_{M}}{\omega L_{M}}\left(V_{M}-V_{C} \cos (\delta)\right)$

\section{Simulation Results}

Steady state:

Common Bus: $400 \mathrm{~V}, 50 \mathrm{~Hz}, \cos (\varphi)=1$,

Diesel Generator: $60 \mathrm{~kW}, 18 \mathrm{kVAR}$

Wind Generator: $30 \mathrm{~kW},-18 \mathrm{kVAR}$,

Photovoltaic inverter: $0 \mathrm{~kW}, 0 \mathrm{kVAR}$

Capacitor: $0 \mathrm{~kW}, 30 \mathrm{kVAR}$,

Load: $90 \mathrm{~kW},-30 \mathrm{kVAR}$

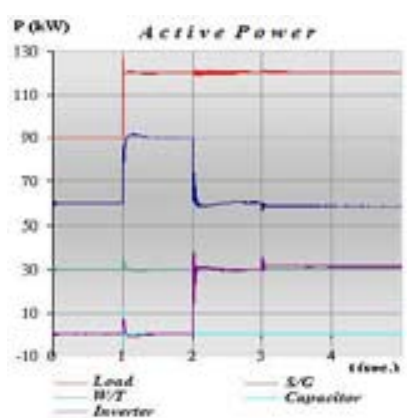

Fig. 3 Active Power $\mathbf{P}$

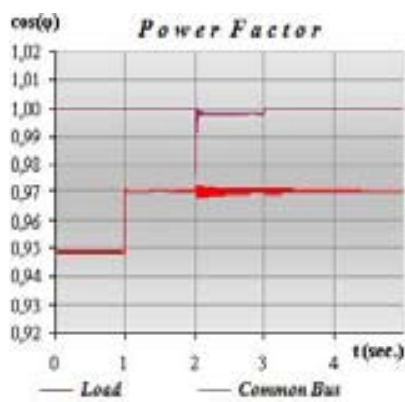

Fig. 5 Power Factor $\cos (\varphi)$

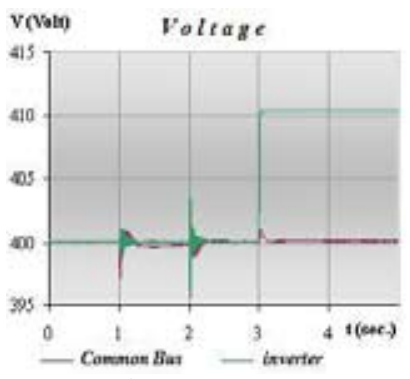

Fig. 7 Voltage V

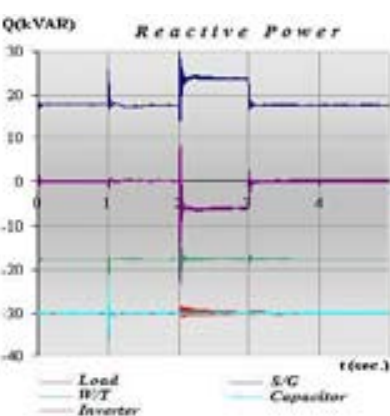

Fig.4 Reactive Power Q

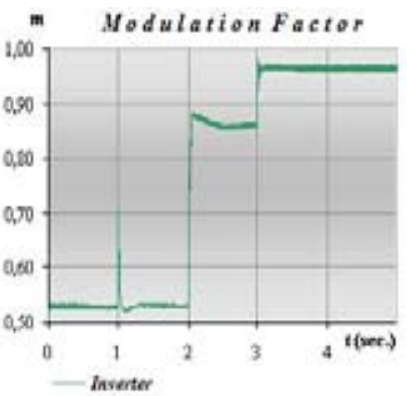

Fig. 6 Modulation Factor $\mathrm{m}$

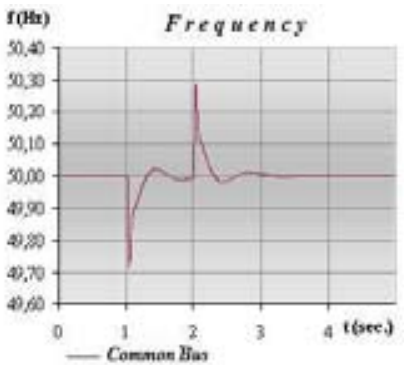

Fig. 8 Frequency $f$
In Fig.3-4, the variations of the active and the reactive power, during the transition from one initial steady state to another are illustrated. In Fig.5, the Power Factor in the common bus of the load is illustrated. In Fig.6, the Modulation Factor $\mathrm{m}$ of the inverter is illustrated. In Fig.7, the Volt- 
age $\mathrm{V}$ is illustrated. In Fig.8, the Frequency $\mathrm{f}$ is illustrated. The system behavior is relatively stable and it returns to a steady state condition in a very short period of time.

At time $\mathrm{t}=1 \mathrm{sec}$, and after the system has reached a steady state condition, a step increase of $30 \mathrm{~kW}$ in active power of the load is imposed (figure 3 ). This sudden change in load demand results in oscillations of the real power provided by the conventional generating units. Finally, the real power demand is covered by the system's conventional power generation.

At time $\mathrm{t}=2 \mathrm{sec}$, the power flow is controlled by regulating the phase difference $(\delta)$ between the converter voltage and the grid voltage. The figure 6 shows the deviation of modulation factor $\mathrm{m}$ introduced by the inverter which is necessary for real power regulation purposes.

Finally, at time $\mathrm{t}=3 \mathrm{sec}$, a sudden increase in output inverter voltage from $400 \mathrm{~V}$ to $410 \mathrm{~V}$ (figure 7) is imposed. This change is capable to eliminate the reactive power flow throw the mutual impedance and to reestablish the perfect power factor, $\cos (\varphi)$ (figure 5$)$ in the common bus.

\section{Conclusions}

The simulation results of a hybrid power system with diesel and wind power generation and a grid connected photovoltaic (PV) inverter, presented in this paper, demonstrate that the modular simulation system, developed using the matlab programming environment, constitutes a very useful tool for analysis and design of such systems. Using this tool, a designer can easily develop control strategies to balance the system power flows under different generation/load conditions. The study of the dynamic behavior of such system, is of primary importance for the determination of the higher penetration limits of wind turbines and PV generators, the selection of the control and protection equipment, so that acceptable performance of the system is achieved. Simulation studies, using the proposed control approach, indicate that application of these policies may result in reduced load flowing requirements for conventional power generation units, and improve power quality and stability of the interconnected systems.

\section{References}

1. K.E. Yeager, J.R. Willis: "Modeling of emergency diesel generators in an 800 megawatt nuclear plant", IEEE Transactions on Energy Conversion, Vol. 8, No. 3, September 1993.

2. K.C. Kalaitzakis, G. J. Vachtsevanos: "On the control and stability of grid connected photovoltaic sources", IEEE Transactions on Energy Conversion, Vol. EC-2, No. 4, December 1987.
3. Chemmangot V. Nayar, Mochamad Ashari, W. W. L. Keerthipala: "A grid-interactive photovoltaic uninterruptible power supply system using battery storage and a back up diesel generator", IEEE Transactions on Energy Conversion, Vol. 15, No. 3, September 2000 . 